University of Nebraska - Lincoln

DigitalCommons@University of Nebraska - Lincoln

USDA National Wildlife Research Center - Staff

Publications

U.S. Department of Agriculture: Animal and Plant Health Inspection Service

January 2005

\title{
Indexing principles and a widely applicable paradigm for indexing animal populations
}

Rlchard M. Engeman

USDA-APHIS-Wildlife Services, s_r100@yahoo.com

Follow this and additional works at: https://digitalcommons.unl.edu/icwdm_usdanwrc

Part of the Environmental Sciences Commons

Engeman, RIchard M., "Indexing principles and a widely applicable paradigm for indexing animal populations" (2005). USDA National Wildlife Research Center - Staff Publications. 45.

https://digitalcommons.unl.edu/icwdm_usdanwrc/45

This Article is brought to you for free and open access by the U.S. Department of Agriculture: Animal and Plant Health Inspection Service at DigitalCommons@University of Nebraska - Lincoln. It has been accepted for inclusion in USDA National Wildlife Research Center - Staff Publications by an authorized administrator of DigitalCommons@University of Nebraska - Lincoln. 


\title{
Indexing principles and a widely applicable paradigm for indexing animal populations
}

\author{
Richard M. Engeman \\ National Wildlife Research Center, 4101 LaPorte Avenue, Fort Collins, CO 80521-2154, USA. \\ Email: richard.m.engeman@aphis.usda.gov
}

\begin{abstract}
Monitoring animal populations is an essential component of wildlife research and management. Population indices can be efficient methods for monitoring populations when more labour-intensive densityestimation procedures are impractical or invalid to apply, and many monitoring objectives can be couched in an indexing framework. Indexing procedures obtain maximal utility if they exhibit key characteristics, including being practical to apply, being sensitive to changes or differences in the target species' population, having an inherent variance formula and allowing for precision in index values, and relying on as few assumptions as possible. Additional useful characteristics include being able simultaneously to monitor multiple animal species and to describe spatial characteristics of the species monitored. Here, a paradigm is presented that promotes the characteristics that make indices most useful. Observations are made at stations located throughout the area of interest. Stations can take many forms, depending on the observations, and range from points for visual counts to tracking plots to chew cards, and many others. A wide variety of observation methods for many animal species can fit into this format. Observations are made at each station on multiple occasions for each indexing session. Geographic location data for each station are encouraged to be collected. No assumptions of independence are made among stations, nor among observation occasions. Measurements made at each station are required to be continuous or unboundedly discrete. The formula for a general index to describe population levels is presented and its variance formula is derived. Issues relevant to the application of this methodology, and indices in general, are discussed.
\end{abstract}

\section{Introduction}

Monitoring animal populations is crucial to wildlife rescarchers and managers for a wide spectrum of reasons. including setting harvest-management parameters, assessing biodiversity. tracking threatened or endangered species. discase surveillance, management of wildlife in conflict with human interests, compliance with regulatory requirements. and the general accumulation of knowledge. Ideally, the cxact number of animals within an area of interest would be known but, in reality. this is a rare circumstance and population sioe is often assessed through sampling proeedures. Density-estimation procedures such as mark-capture (c.g. Otis et al. 1978) and line transect (c.g. Burnham et al. 1980) methods attempt to estimate the actual number or density of animals in an area, but they are often difficult or expensive to implement for many animal speeies. and they may require difficult-to-meet analytical assumptions that. when violated. result in estimates of questionable quality (sce Krebs 1998 and Leidloff 2000 for an examination of potential problems with mark-recapture methods and Burnham et al. 1980 for a similar discussion on line-transect methods). (Often. problems couched in terms of absolute density can be redefined such that an index parameter reflective of population abundance will provide an efficient solution (Caughley 1977; Krebs 1998). Indexing procedures are additional tools in the armancontarum of methods at ailable for monitoring wildlife populations (c.g. Engeman 2003). Examples include tracking rates, faces depostion. capture rates, bait consumption, or visual observations, among a host of possibilities. Because indices ane not estminates of actual population numbers, they are applied to make relative comparisons between populations or to momiter trends w thin a population (c.g. Caughley 1977; Krebs 1998).

Here, a general observationat and analywal paradign is presented into which a wide variety of measurement methods for indexing many species of anmals cin fil. The data structure from which index values are calculated leads to the derivation of the mex variance entmiate while regur ing minimal analytical assumptions about the observations.

\section{Desirable qualities for an index}

An indexing methodology obtains maximal utility when it possesses certain desirable characteristics. Some of these result from the data structure or the analytical method. whereas others can result from observational methods.

Practicality: An index method must be practical to apply. This might be said of any sampling procedure but, beyond that, practicality is a prime deciding factor for choosing to use an index in the first place. The index method should be userfriendly, with the procedures and concepts for recording 
information easily understood, and with little chance for confusion among species. Methods must impose minimal inconvenience on landowners and managers to be acceptable.

Sensitivity. An index should be sensitive to differences in population size, whether making simultaneous comparisons among multiple populations, or monitoring for change within the same population. That is, the measurements upon which the index is based should change if the population changes. For example, structure counts often are used as indices to compare muskrat (Ondatra zibethicus) populations between areas (Proulx and Gilbert 1984). However, the longevity of structures built by muskrats make structure counts an inefficient method to index short-term changes within muskrat populations, whereas rigorously designed visual counts may provide suitable sensitivity for this application (Engeman and Whisson 2003).

Precision and variance estimation. Given an appropriate observation, the ability of an index to statistically detect population differences increases with its precision. This highlights a contrast between density estimation and indexing. Density estimation strives to identify actual population abundance directly, whereas indexing procedures seek to use reflective measures for detecting differences in abundance. Thus, general applications for density estimation place a premium on accuracy (low bias), but the applications for indices make precision of the utmost importance (e.g. Caughley and Sinclair 1994). An index that is easily applied in the field will likely encourage more observations, with a consequent improvement in precision.

Since precision is essential to an index, it follows that the data structure, measurements and index calculations define an inherent estimate of variance, which in turn allows for the application of standard statistical procedures. Often a situation exists where observations are made and an index produced, but the only avenue for estimating variance is to first subdivide the data into units that can contribute to the variance calculations. This approach, especially if done post hoc, can produce variance estimates that vary subjectively with the definition of the units.

Robustness. The most robust inferences are produced if the calculated index and associated variance are burdened with as few assumptions as possible about the data structure and the distribution of the observations. Violation of analytical assumptions is the bane of density-estimation methods (see Krebs 1998 for a general overview), and can be a compelling reason to apply an index rather than estimating density. An index heavily reliant on analytical assumptions is of minimal use to the investigator.

Other useful characteristics. Other characteristics can make an indexing procedure more informative. First, if the observation methods allow simultaneous monitoring of multiple species, then economy of effort is achieved over simultaneously applying different methods for different species. Also, if information on geographic location is col- lected along with the index observations, then spatial characteristics of the population(s) may also be described.

\section{General index format}

A tremendous array of indexing procedures has been applied to many species of animals. Each combination of observation, sampling frame and computation procedure results in a parameter estimate for a population characteristic that is reflective of animal abundance. Here, an indexing paradigm is provided with a sampling structure in which many existing, or new, observation and measurement methods can be couched so that the calculated estimates (index values) possess useful statistical properties. The key components to this paradigm are defining where the observations are taken, the time dimension for taking observations, the measurements to make, and the data structure and analytical procedures for calculating an index and its variance estimate.

\section{Observation stations}

The locations where observations are taken will be referred to generically as stations. In practice, for example, each station might be a plot for observing tracks or other animal sign, a tracking tile, a chew card, a point where animal counts are made, a site where bait consumption is measured, a camera location, or even a trap line.

To index a population within an area, observation stations should be set throughout the survey area of interest. That being said, the distribution of observation stations must be carefully considered relative to efficiency in obtaining adequate measurement of the animals being monitored, and avoiding bias in the results that could be induced by station placement. Rarely do animals operate in a spatially random pattern. Station locations may take advantage of behavioural characteristics by placement where they would most likely intersect the usual activities of the target animals (Engeman et al. 2002). This is similar in concept to the capture of animals. Capture devices are not placed with complete randomness, but rather are placed where an animal is most likely to encounter the capture device. Consider a tracking plot example for collecting index data. Many species such as canids preferentially use dirt roads or tracks as travel ways. Placement of stations along such travelways is an efficient means to obtain observations. If such travelways are distributed throughout the area of interest, they can provide a means for station placement that is an efficient and representative sampling of the population using the surrounding habitat. Care and common sense must be applied when choosing to take advantage of these behavioural characteristics for monitoring animals. If roads or tracks are not dispersed through the area of interest, then observations only from them would not be representative of the population throughout the area. If multiple indexing assessments are to be made through time on the same area, then the same station locations should be used if possible (e.g. Ryan and Heywood 
2003). If the area of interest is comprised of different habitat types, then it is advisable to stratify station placement according to habitat type, thus helping to ensure that the calculated index reflects the population throughout the area rather than being overly biased towards (or away from) a particular subset of habitat. Stratification also allows index comparisons among the habitats within the area of interest, information about which is often of biological and management importance.

Stations should be dimensionally consistent in preparation. This applies to area dimensions of the stations, as well as to time, weight or any other characteristic of the stations. Thus, not only should stations such as tracking plots, tracking tiles or chew cards have consistent sizes (e.g. rectangular dimensions), but chew cards should all have the same thickness, bait-take stations should each start with the same amount of bait, stations for making animal counts should be observed for the same length of time and out to the same distance.

\section{Time dimension}

Animal activity often is variable over even short periods. Thus, to account for variability over time, the stations are best observed on more than one occasion during an assessment period. Typically, this means taking measurements at each station on each of multiple days, but for some applications this could mean taking measurements every other day, or multiple times during a day, or at some other period. For simplicity, the time dimension will be referred to here as a day effect, representing a common situation where observations at each indexing session would be made on multiple, usually consecutive, days. The time elapsed between successive observations at each station should remain constant. For example, assume observations are to be made at three time points. The time lapsed for accumulation of data should be constant at each of the three observation times. Say tracking plots are to be observed $24 \mathrm{~h}$ after plot preparation, then each succeeding observation of the plots should also be made $24 \mathrm{~h}$ after plot preparation.

\section{Measurements}

Many types of measurements can fit the above observational structure, including the general categories of animal counts, measurement of animal sign, and catch per unit effort. For the purposes of the methodology presented here, the observations taken at each station should be non-binary, that is, continuous or unboundedly discrete. The variety of nonbinary indexing measurements at different types of observation stations include the number of intrusions by each species of animal onto a dirt tracking plot, the area or proportion of a tracking tile tracked by each species, the proportion or area of a chew card consumed, the number of individuals of each species observed in a fixed amount of time within a fixed distance at each station (standardised by time of day), or the daily number of captures or catch rate from each of a number of trap lines in the area of interest (e.g. Allen et al. 1996; Engeman and Witmer 2000; Engeman and Whisson 2003).

Often, potentially continuous measures have been neglected in favour of binary observations, i.e. presence-absence measures at each station. Reduction of potentially continuous data to binary observations is easily demonstrated to have less descriptive ability and result in a greater opportunity for erroneous inferences (Engeman et al. 1989), and this principle has been well demonstrated for tracking-plot data (e.g. Allen et al. 1996; Engeman et al. 2000, 2002).

Binary observations have often been made because a continuous measurement was difficult to measure or was not considered. For example, tracking tiles or chew cards are easier to record as showing activity or not, without accurately recording the intensity of activity at each station. Observations on intensity of activity at these types of stations may be made by measuring the area of activity at each station. This measurement can be reliably approximated by counting the squares on an overlaid grid showing activity. Moreover, the universality of modern computing equipment makes highly accurate area measurements a relatively simple process using commonly available software.

A corollary to the use of continuous rather than binary measures is that stations should be designed so that total saturation at a station is unlikely. That is, an entire chew card would be unlikely to be consumed overnight, not all bait at a bait station would be consumed, or a tracking tile would not be totally obliterated by animal activity. All stations can receive activity, but an increase in intensity can still be detected.

Another valuable measure at each station is its geographical location. This can be accomplished by the use of global positioning devices, maps, or relative measurements among station locations. Potentially, measuring or calculating distances among stations can be used in conjunction with station observations to also index the spatial pattern of animal activity within the survey area. One approach modifies Hopkins' (1954) index of aggregation, which has seen other useful modifications (e.g. Engeman and Sugihara 1998). The IP (for index of pervasiveness) is defined mathematically as:

$$
I P=(1 / n) \Sigma\left(w_{1} / w_{2}\right),
$$

where $n$ is the number of active stations, $w_{1}$ is the square of the distance from an active tracking station to the nearest active station (nearest neighbour sample: Engeman et al. 1994), and $w_{2}$ is the square of the distance from that nearest station to its nearest active station (second-nearest neighbour sample: Engeman et al. 1994). When the pattern is entirely random, $I P=1$. If the stations with activity show aggre- 
gations (localised concentrations), then IP $>1$. For systematic spatial patterns of activity, IP $<1$.

\section{Data structure}

The data structure, defined by the station placement design and measurement method, provides the framework from which a general index and its variance can be calculated. To formalise a mathematical description of the data structure, assume there are $s$ stations at which observations will be made on each of $d$ time points (days). The measurement from the $i$ th station on the $j$ th day, $x_{i j}$, can be represented as a linear model:

$$
\mathrm{x}_{i j}=\mu+\mathrm{S}_{i}+\mathrm{D}_{j}+\mathrm{e}_{i j},
$$

where the term $\mu$ is the overall mean measurement value per station per day for the area being assessed. $D_{j}$ is a random effect due to the day on which an observation was made, with $j=1,2,3 \ldots d . \mathrm{S}_{i}$ is a random effect due to the $i$ th station with $i-1,2,3 \ldots s_{j} \leq s$ representing the number of stations contributing data on the $j$ th day. The $e_{i j}$ represent random observational noise, and are considered independent and identically distributed with mean $=0$ and variance $=\sigma_{\mathrm{e}}{ }^{2}$.

In practice, it would be unreasonable to assume that each station would contribute data each day. Tracking plots can be obliterated by livestock or vehicle traffic. Chew cards can become lost. Observations at some stations may be missed owing to unforeseen access restrictions. Thus, the number of stations contributing data each day is allowed to vary.

To assume that stations are uncorrelated, or that observation days are uncorrelated, would be biologically unreasonable in most circumstances. For example, animals may roam greater distances than those separating the stations. Also, stations that are closer together may share more characteristics than do more distantly separated stations. Similarly, environmental or climatic conditions should not be assumed to be unrelated across days of observation. The stations in this sampling framework are not assumed independent of each other nor are days assumed independent of each other, i.e. a non-zero covariance structure is assumed to exist among stations and among days. Thus, the derivation of the variance estimate is not reliant on a potentially unrealistic assumption of independence.

\section{Index calculations}

The calculation of the general index (GI) begins by taking the mean of the observations across all stations each day (this is done separately for each species if more than one is measured at each station). The GI is the mean of the daily means, and provides an average view of the measurements over space and time within the area of interest. The GI can be written in the linear model terminology as:

$$
\mathrm{GI}=\frac{1}{d} \sum_{j}^{d} \frac{1}{s j} \sum_{i}^{y} x_{i j}
$$

The variance formula for the GI is:

$$
\operatorname{var}(\mathrm{Gl})=\frac{\sigma_{s}^{2}}{d} \sum_{j}^{\prime l} \frac{1}{s j}+\frac{\sigma_{d}^{2}}{d}+\frac{\sigma_{e}^{2}}{d^{2}} \sum_{j}^{\prime} \frac{1}{s j}
$$

where the $\sigma_{s}{ }^{2}, \sigma_{d}{ }^{2}$, and $\sigma_{e}{ }^{2}$ are, respectively, the components for station-to-station variability, daily variability, and random observational variability associated with each station each day. A computational procedure such as SAS PROC VARCOMP (SAS Institute 1996), using a restricted maximum-likelihood estimation procedure (REML), can be used to calculate the variance components (Searle et al. 1992) needed in the GI variance-estimation formula. If all $s$ of the tracking stations provide observations each day, the formula simplifies to:

$$
\operatorname{var}(\mathrm{Gl})_{\mathrm{equal}}=\frac{\sigma_{s}^{2}}{s}+\frac{\sigma_{d}^{2}}{d}+\frac{\sigma_{e}^{2}}{s d}
$$

The existence of an inherent variance estimate for Gl allows standard statistical procedures such as confidence intervals and hypothesis tests to be applied, as appropriate. Appendix 1 provides an example for calculating the Gl and its variance.

\section{Discussion}

Population indexing and density estimation are among the population-monitoring tools available to the investigator (Engeman 2003). An investigator needs to be clear on the monitoring objectives when deciding whether to estimate the numerical size or density of the population, or whether to apply an index reflective of the population. Given that an indexing procedure would be suitable for the situation, a great diversity of observation and measurement methods can be integrated into the general index procedures presented here, as illustrated in Table 1.

Although indices are valuable for detecting differences in population abundances, they are not estimates of the numerical abundance. An attempt to estimate actual abundance or density from an index would require additional study where known densities (not density estimates) are related to index values with a statistical model. Although frequently seen in the wildlife literature, attempting to define a relationship between an index and true population numbers by establishing a relationship between an index and an estimate of density is inappropriate, because this yields only an indication of correspondence among methods, with the benchmark still only an estimate of unknown quality (e.g. Caughley and Sinclair 1994; Leidloff 2000).

If a population estimate is mandatory, then it is sensible initially to devote the resources necessary for density or abundance estimation. As White (2001) cautioned, 'Don't even start the project if you can't do it right'. The investigator should be prepared to do all that is necessary in terms of resources and information to adequately design a study that ensures that adequate numbers are observed or captured, and 
that data are appropriately modelled without violating the underlying assumptions for calculating the density estimate. This is not a simple task. McKelvey and Pearson (2001) found in a five-year literature review of small mammal studies that $98 \%$ of the studies resulted in too few data for valid mark-recapture population estimation. Such frequent difficulties in meeting the requirements for densityestimation procedures led Caughley and Sinclair (1994) to assert that absolute estimates of population size or density require a 'leap of faith' by the manager concerning the validity of analytical assumptions and the resulting accuracy of estimates.

Application of the paradigm for data gathering and index calculation goes a long way towards ensuring that the resulting index will possess many of the desirable qualities described earlier. Nevertheless, a useful data structure and analytical procedures by themselves do not guarantee that an indexing method is suitable for meeting objectives. Considerable room exists for artistry by the investigator in deciding on the measurements to take and how to place the stations. Sometimes a number of methods may be available from which the most appropriate method must be selected. On the other hand, a proven method may not be available. A method successfully applied to a similar species or a similar situation would be a good candidate method to test and apply.

Fully enumerated wild populations upon which methods can be tested are rare. Therefore, examination of the utility of an indexing procedure is properly approached through experimentation. A straight-forward strategy is to index a population, change that population, and then index the population again. This can be repeated multiple times and is best if a control area with no induced population change is simultaneously monitored using the same indexing method.

An index should increase if the population increases and decrease if it decreases. Therefore, an index needs to be monotonic relative to the true population to effectively discern differences. Ideally, the index would have a linear relationship with the population size, but to assume linearity for analytical purposes would transform an index method into a density-estimation method, with all of the associated difficulties concerning analytical assumptions. The resultant variability of an index determines the statistical detectability of population differences. As long as they do not interfere with one another, simultaneous application of multiple procedures provides comparisons on how each follows population changes. A method would be selected on the basis of its sensitivity to population differences and field logistics. If a seemingly reasonable station placement and observation method do not produce useful results, then minor changes in methods may improve sensitivity to the presence of animals. For example, a chew card might receive little attention by the animal of interest even though populations are high. A change in the impregnating substance could result in an improved response. But clearly, a chew card index calculated from responses using one impregnating substance is an entirely different index, and not comparable with, an index calculated from responses using a different impregnating substance.

Many of the observational methods that can fit into the GI format are suitable for simultaneously monitoring multiple species of animals (e.g. tracking stations, visual counts). Simultaneous monitoring of multiple species allows infer-

Table 1. Examples of the diversity of animals and observation procedures encompassed by the general indexing paradigm

\begin{tabular}{|c|c|c|c|}
\hline Station example & $\begin{array}{l}\text { Potential (non-binary) } \\
\text { measurement }\end{array}$ & $\begin{array}{l}\text { Examples of potential } \\
\text { species observed }\end{array}$ & $\begin{array}{l}\text { Example citations for the type of station } \\
\text { or measurement }\end{array}$ \\
\hline Dirt tracking plots & $\begin{array}{l}\text { Number of intrusions by each } \\
\text { species into plot }\end{array}$ & $\begin{array}{l}\text { Medium to large mammals } \\
\text { (e.g. carnivores, ungulates, } \\
\text { macropods) }\end{array}$ & $\begin{array}{l}\text { Allen et al. (1996), Engeman et al. (2000), } \\
\text { (2001), (2003a), (2003b); } \\
\text { Mahon et al. (1998) }\end{array}$ \\
\hline Tracking tiles/plates & $\begin{array}{l}\text { Proportion/area tile tracked } \\
\text { each species }\end{array}$ & $\begin{array}{l}\text { Rodents, small to medium-sized } \\
\text { carnivores }\end{array}$ & $\begin{array}{l}\text { Barret (1983), Fiedler (1994); } \\
\text { Zielinski and Kucera (1995) }\end{array}$ \\
\hline Mound count plot & $\begin{array}{l}\text { Number of mounds or feeder } \\
\text { plugs in plot }\end{array}$ & Pocket gophers & $\begin{array}{l}\text { Reid et al. (1966); Anthony and Barnes (1983); } \\
\quad \text { Engeman et al. (1993); }\end{array}$ \\
\hline Chew cards & $\begin{array}{l}\text { Proportion/area removed } \\
\text { (or remaining) }\end{array}$ & $\begin{array}{l}\text { Rodents and other small to } \\
\text { medium-sized mammals }\end{array}$ & $\begin{array}{l}\text { Caughley et al. (1998); } \\
\text { Engeman and Witmer (2000) }\end{array}$ \\
\hline $\begin{array}{l}\text { Visual observation } \\
\text { sites }\end{array}$ & $\begin{array}{l}\text { Number seen within a fixed time } \\
\text { and distance }\end{array}$ & Binds, ground squirrels, muskrats & $\begin{array}{l}\text { Fagerstone and Biggins (1986); } \\
\text { Menkens et al. (1990); Powell et al. (1994); } \\
\text { Robbins et al. (1986); } \\
\text { Severson and Plumb (1998); } \\
\text { Servoss et al. (2000); } \\
\text { Engeman and Whisson (2003) }\end{array}$ \\
\hline Bait take & $\begin{array}{l}\text { Amount or proportion of } \\
\text { bait removed }\end{array}$ & Rodents, swine, deer, bear & Chitty (1954); Choquenot et al. (1996) \\
\hline Apple slice(s) & $\begin{array}{l}\text { Amount or proportion of } \\
\text { apple removed }\end{array}$ & Voles & Byers (1975); Tobin et al. (1992) \\
\hline Road segment & $\begin{array}{l}\text { Number of scats deposited in } \\
\text { fixed time frame }\end{array}$ & Canids & Davison (1980); Andelt and Andelt (1984) \\
\hline
\end{tabular}


Table 2. Number of dingo track intrusions observed on four consecutive days from 50 tracking stations on a cattle station in south-west Queensland, Australia

\begin{tabular}{|c|c|c|c|c|c|c|c|c|c|}
\hline Station $\#$ & Day 1 & Day 2 & Day 3 & Day 4 & Station \# & Day 1 & Day 2 & Day 3 & Day 4 \\
\hline 1 & 1 & 1 & 2 & 6 & 26 & 1 & 0 & 0 & 0 \\
\hline 2 & 1 & 1 & 3 & 5 & 27 & 1 & 0 & 0 & 0 \\
\hline 3 & 3 & 1 & 3 & 4 & 28 & 0 & 3 & 2 & 1 \\
\hline 4 & 1 & 1 & 4 & 1 & 29 & 4 & 2 & 0 & 0 \\
\hline 5 & 3 & 0 & 4 & 3 & 30 & 3 & 0 & 0 & 3 \\
\hline 6 & 4 & 0 & 4 & 0 & 31 & 5 & 0 & 0 & 0 \\
\hline 7 & 1 & 0 & 4 & 0 & 32 & 5 & 0 & 2 & 0 \\
\hline 8 & 0 & 1 & 0 & 0 & 33 & 2 & 1 & 3 & 0 \\
\hline 9 & 0 & 0 & 1 & 0 & 34 & 4 & 0 & 2 & 1 \\
\hline 10 & 0 & 0 & 0 & 0 & 35 & 3 & 0 & 0 & 1 \\
\hline 11 & 0 & 1 & 1 & 0 & 36 & 0 & 2 & 2 & 0 \\
\hline 12 & 0 & 2 & 0 & 0 & 37 & 0 & 1 & 3 & 1 \\
\hline 13 & 0 & 2 & 1 & 0 & 38 & 0 & 0 & 0 & 1 \\
\hline 14 & 0 & 0 & 2 & 0 & 39 & 0 & 0 & 1 & 0 \\
\hline 15 & 0 & 1 & 2 & 0 & 40 & 0 & 1 & 2 & 1 \\
\hline 16 & 0 & 2 & 0 & 1 & 41 & 0 & 1 & 1 & 1 \\
\hline 17 & 0 & 0 & 0 & 1 & 42 & 1 & 1 & 1 & 1 \\
\hline 18 & 0 & 2 & 3 & 0 & 43 & 1 & 1 & 0 & 4 \\
\hline 19 & 0 & 1 & 3 & 0 & 44 & 0 & 1 & 0 & 0 \\
\hline 20 & 2 & 0 & 2 & 0 & 45 & 0 & o & 0 & 1 \\
\hline 21 & 0 & 4 & 1 & 0 & 46 & 0 & 0 & 0 & 1 \\
\hline 22 & 1 & 0 & 1 & 0 & 47 & 0 & 2 & 1 & 2 \\
\hline 23 & 0 & 0 & 0 & 0 & 48 & 0 & 1 & 0 & 0 \\
\hline 24 & 0 & 0 & 1 & 0 & 49 & 0 & 2 & 0 & 0 \\
\hline 25 & 0 & 2 & 2 & 0 & 50 & 0 & 0 & 1 & 1 \\
\hline Mean & & & & & & 0.94 & 0.82 & 1.30 & 0.82 \\
\hline
\end{tabular}

ences on relative population levels within each species, but comparisons of index values across species is not appropriate. For example, consider monitoring multiple species using intrusions to tracking plots on dirt roads. Different species would have different home ranges, road usage, and travel rates. Spoor-deposition rates, and hence GI values, would differ among species even if their populations were the same.

The variance components calculated for use in the GI variance formula also provide helpful planning information (e.g. Searle et al. 1992). The relative contributions of stationto-station variation and day-to-day variation can be examined to optimise the combination of days and stations for subsequent indexing assessments. For example, if the component of variance for station-to-station variation was much larger than the other sources of variation, then the emphasis would be placed on the number of stations. However, if the weather changed during the assessment period, then the number of observation days should be increased, or the assessment delayed. In reality, logistics and resources often are the most important influences on sampling designs for wildlife surveys.

The applications of the indexing methodology described here have been exemplified by vertebrate animal populations, but the methodology is more broadly applicable. Invertebrate animals can be indexed by this paradigm using standard entomological methods. The observation stations could be pitfall traps or standardised sweep-net collections, with the measurements being daily counts at each station of number of species, or number of insects of each species. The same tracking plots as have been used to index populations of vertebrate predators of marine turtle nests (Engeman et al. $2003 b$ ) could have been applied to index crab populations, which also represent a substantial predation threat to the turtle nests (Stancyk 1982). The GI also holds many general ecological applications. Stations could be sediment or litter traps to index daily deposition in streams or elsewhere. Similarly, various plot and measurement configurations could index leaf, needle or seed fall in plant communities. As long as a suitable layout of stations is designed and appropriate observations are made, the methods summarised here provide a straight-forward indexing procedure with useful quantitative properties.

\section{Acknowledgments}

J. Bourassa and M. Pierce provided valuable help with identifying software for measuring areas. K. Fagerstone, B. Kimball, T. Mathies, R. Sterner and K. VerCauteren provided helpful reviews of the manuscript.

\section{References}

Allen, L., Engeman, R. M., and Krupa, H. (1996). Evaluation of three relative abundance indices for assessing dingo populations. Wildlife Research 23, 197-206. 
Andelt, W. F., and Andelt, S. H. (1984). Diet bias in scat deposition rate surveys of coyote density. Wildlife Society Bulletin 12, 74-77.

Anthony, R. M., and Barnes, V. G. Jr (1983). Plot occupancy for indicating pocket gopher abundance and conifer damage. In "Vertebrate Pest Control and Management Materials: Fourth Symposium, ASTM STP 817' (Ed. D. E. Kaukeinen.) pp. 247-255. (American Society for Testing and Materials: Philadelphia, PA.)

Barret, R. H. (1983). Smoked aluminum track plots for determining furbearer distribution and relative abundance. California Department of Fish and Game 69, 188-190.

Burnham, K. P., Anderson, D. R., and Laake, J. L. (1980). Estimation of density from line transect sampling of biological populations. Wildlife Monographs 72, 1-202.

Byers, R. E. (1975). A rapid method for assessing pine vole control in orchards. Horticulture Science 10, 391-392.

Caughley, G. (1977). 'Analysis of Vertebrate Populations.' (Wiley \& Sons: New York.)

Caughley, G., and Sinclair, A. (1994). 'Wildlife Ecology and Management.' (Blackwell Science: Cambridge, MA.)

Caughley, J., Donkin, C., and Strong, K. (1998). Managing mouse plagues in rural Australia. In 'Proceedings of the Eighteenth Vertebrate Pest Conference'. pp. 160-165.

Chitty, D. (1954). 'Control of Rats and Mice.' (Clarendon Press: Oxford, UK.)

Choquenot, D., Mcllroy, J., and Korn, T. (1996). 'Managing Vertebrate Pests: Feral Pigs.' (Bureau of Resource Sciences, Australian Government Publishing Service: Canberra.)

Davison, R. P. (1980). The effects of exploitation on some parameters of coyote populations. Ph.D. Thesis, Utah State University, Logan, UT.

Engeman, R. M. (2003). More on the need to get the basics right: population indices. Wildlife Society Bulletin 31, 286-287.

Engeman, R. M., and Sugihara, R. T. (1998). Optimization of variable area transect sampling using Monte Carlo simulation. Ecology 79, $1425-1434$.

Engeman, R. M., and Whisson, D. A. (2003). A visual method for indexing muskrat populations. International Biodeterioration \& Biodegradation 52, 101-106. doi:10.1016/S0964-8305(03)00031-3

Engeman, R. M., and Witmer, G. W. (2000). IPM strategies: indexing difficult to monitor populations of pest species. 'Proceedings of the Nineteenth Vertebrate Pest Conference'. pp. 183-189.

Engeman, R. M., Campbell, D. L., and Evans, J. (1993). A comparison of 2 activity measures for northern pocket gophers. Wildlife Society Bulletin 21, 70-73.

Engeman, R., Sugihara, R., Pank, L., and Dusenberry, W. (1994). A comparison of plotless density estimators using Monte Carlo simulation. Ecology 75, 1769-1779.

Engeman, R. M., Otis, D. L., Bromaghin, J. F., and Dusenberry, W. E. (1989). On the use of the $\mathrm{R}_{50}$. In 'Vertebrate Pest Control and Management Materials. Vol. 6, STP1055'. (Eds K. Fagerstone and R. Curnow.) pp. 13-18. (American Society for Testing and Materials: Philadelphia, PA.)

Engeman, R. M., Pipas, M. J., Gruver, K. S., and Allen, L. (2000). Monitoring coyote populations with a passive activity index. Wildlife Research 27, 553-557.

Engeman, R. M., Constantin, B., Nelson, M., Woolard, J., and Bourassa, $J$. (2001). Monitoring changes in feral swine population and spatial distribution of activity. Envimnmental Conservation 28, 235-240.

Engeman, R. M., Pipas, M. J., Gruver, K. S., Bourassa, J., and Allen, L. (2002). Plot placement when using a passive tracking index to simultaneously monitor multiple species of animals. Wildlife Research 29, 85-90. doi:10.1071/WR01046
Engeman, R. M., Christensen, K. L., Pipas, M. J., and Bergman, D. L. (2003a). Population monitoring in support of a rabies vaccination program for skunks in Arizona. Journal of Wildlife Diseases 39 746-750.

Engeman, R. M., Martin, R. E., Constantin, B., Noel, R., and Woolard. J. (2003b). Monitoring predators to optimize turtle nest protection through control. Biological Conservation 113, 171-178. doi:10.1016/S0006-3207(02)00295-1

Fagerstone, K. A., and Biggins, D. E. (1986). Comparison of capture-recapture and visual count indices of prairie dog densities in black-footed ferret habitat. Great Basin Naturalist Memoirs 8. 94-98.

Fiedler, L. A. (1994). 'Rodent Pest Management in Eastern Africa.' (Food and Agriculture Organization of the United Nations: Rome.)

Hopkins, B. (1954). A new method for determining the type of distribution of plant individuals. Annals of Botany 18, 213-227.

Krebs, C. J. (1998). 'Ecological Methodology.' (Benjamin/Cummings: Menlo Park, CA.)

Leidloff, A. C. (2000). Habitat utilisation by the grassland melomys (Melomys burtoni) and the swamp rat (Rattus lutrelus) in a coastal heathland of Bribie Island, south-east Queensland. Ph.D. Thesis, Queensland University of Technology, Brisbane.

Mahon, P. S., Banks, P. B., and Dickman, C. R. (1998). Population indices for wild carnivores: a critical study in sand dune habitat, south-western Queensland. Wildlife Research 25, 11-22. doi:10.1071/WR97007

McKelvey, K. S., and Pearson, D. E. (2001). Population estimation with sparse data: the role of estimators versus indices revisited. Canadian Journal of Zoology 79, 1754-1765. doi:10.1139/cjz-7910-1754

Menkens, G. E., Jr, Biggins, D. E., and Anderson, S. H. (1990). Visual counts as an index of white-tailed prairie dog density. Wildlife Society Bulletin 18, 290-296.

Otis, D. L., Burnham, K. P., White, G. C., and Anderson, D. R. (1978). Statistical inference from capture data on closed animal populations. Wildlife Monographs 62.

Powell, K. L., Robel, R. J., Kemp, K. E., and Nellis, M. D. (1994). Above ground counts of black-tailed prairie dogs: temporal nature and relationship to burrow entrance density. Journal of Wildlife Management 58, 361-366.

Proulx, G., and Gilbert, F. F. (1984). Estimating muskrat population trends by house counts. Journal of Wildlife Management 48 , 917-922.

Reid, V. H., Hansen, R. M., and Ward, R. L. (1966). Counting mounds and earth plugs to census mountain pocket gophers. Journal of Wildlife Management 30, 327-334.

Robbins, C. S., Bystrack, D., and Geissler, P. H. (1986). The breeding bird survey: its first fifteen years, 1965-1979. Fish and Wildlife Service Research Publication No. 157. (USDI: Washington, DC.)

Ryan, D. A., and Heywood, A. (2003). Improving the precision of longitudinal ecological surveys using precisely defined observational units. Environmetrics 14, 283-293. doi: 10.1002/env.586

SAS Institute (1996). 'SAS/STAT User's Guide.' (SAS Institute: Carey, NC.)

Searle, S. R., Casella, G., and McCulloch, C. E. (1992). 'Variance Components.' (Wiley \& Sons: New York.)

Servoss, W., Engeman, R. M., Fairaizl, S., Cummings, J. L., and Groninger, N. P. (2000). Wildlife hazard assessment at Phoenix Sky Harbor International Airport. International Biodeterioration \& Biodegradation 45, 111-127. doi:10.1016/S0964-8305(00)00056-1

Severson, K. E., and Plumb, G. E. (1998). Comparisons of methods to estimate population densities of black-tailed prairie dogs. Wildlife Society Bulletin 26, 859-866. 
Stancyk, S. E. (1982). Non-human predators of sea turtles and their control. In 'Biology and Conservation of Sea Turtles'. (Ed. K. A. Bjorndal.) pp. 139-152. (Smithsonian Institution Press: Washington, DC.)

Tobin, M. E., Richmond, M. E., and Engeman, R. M. (1992). Comparison of methods for detecting voles under apple trees. Proceedings of the Eastern Wildlife Damage Control Conference 5 , 201-204.

White, G. C. (2001). Why take calculus? Rigor in wildlife management. Wildlife Society Bulletin 29, $380-386$
Zielinski, W. J., and Kucera, T. E. (1995). American marten, fisher lynx, and wolverine: survey methods for their detection. General Technical Report PSW-GTR-157. (USDA/Forest Service: Albany, CA.)

Manuscript received 22 December 2003, accepted 3 March 2005

\section{Appendix 1. Example for calculating the General Index}

The data in Tabie 2 were collected for assessing a dingo population on a cattle station in south-west Queensland, Australia. A sample of $s=50$ tracking plots was placed on dirt roads throughout the study area and observed for $d=4$ consecutive days. The number of track intrusions into each plot by dingoes was observed each day. The average number of sets of intrusions per plot per day were $0.94,0.82,1.30,0.82$ for Days $1,2,3,4$, respectively (Table 2). The GI index value was calculated as:

$$
(0.94+0.82+1.30+0.82) / 4=0.97 .
$$

Application of VARCOMP in SAS produced variance component estimates of $\sigma_{s}^{2}=0.1075, \sigma_{d}^{2}=0.0199$, and $\sigma_{c}^{2}=1.5767$. We can use the equalsample-size formula because all plots were measurable on each of the four days, i.e. $p_{1}=p_{2}=p_{3}=p_{4}=50$ for Days $1-4$. Insertion of the above information into the equal-sample-size equation for var(Gl) yields:

$$
\begin{gathered}
\operatorname{var}(\mathrm{GI})=0.1075 / 50+0.0199 / 4+1.5767 / 200=0.0150 \\
\text { standard error (s.e.) }=0.122 \\
\text { coefficient of variation (c.v.) }=0.126 .
\end{gathered}
$$

